\title{
Investigation of Hyperactivity and Attention Deficit of University Students Who Do Sport Regularly and Do Not Do Sport in Terms Of Some Variances
}

\author{
Zekiye Özkan ${ }^{1}$, Ersin Arslan ${ }^{1}$ \\ Correspondence: Zekiye Özkan, Yuzuncu Yıl University/School of Physical Education and Sports, VAN, Turkey.
}

Received: December 10, 2018

Accepted: January 3, 2019 Online Published: January 18, 2019

doi:10.11114/jets.v7i2.3840

URL: https://doi.org/10.11114/jets.v7i2.3840

\begin{abstract}
Introduction: Hyperactivity and attention deficit are situations which have been seen in individuals recently and affect both academic and life quality of individual negatively. The aim of this study is to determine hyperactivity and attention deficit level of university student who sport regularly and do not sport.

Method: Carried out with scanning model, this study was applied to 353 students, who continue their education at Yuzuncu Yil University during 2017/2018 academic year, including 208 students who sport regularly and 145 students who do not sport. Reliability and validity of Turkish form of WHO's Adult Attention Deficit/Hyperactivity Disorder Self-Report Scale (ASRS-v1.1) was carried out by Dogan et. al. (2009). As statistical method, as well as descriptive statistics, Kruskal Wallis $\mathrm{H}$ test for multiple comparisons and Mann-Whitney U test for paired comparisons were used in the situations in which normality and homogeneity of variances were not provided. $p<0.05$ was determined as significance level.

Findings: When attention deficit $(\mathrm{p}<0.01)$ and hyperactivity $(\mathrm{p}<0.05)$ levels in those who do sport and those who do not do sport were examined, significant difference was found in favor of those who do sport. In examination of hyperactivity levels and attention deficit in terms of academic success, it was found that there was a significant difference in favor of those who have higher academic success $(p<0.05)$. When hyperactivity levels and attention deficit were analyzed in terms of participants' sheltering status, a significant difference was seen in favor of those who stay in a house far from their family $(\mathrm{p}<0.05)$. A significant difference in terms of high school from which participants graduated and in terms of their parents' education level ( $\mathrm{p}>0.05)$.

Conclusion: It has been seen that hyperactivity levels and attention deficit of university students are related to many factors. Today, intensely usage of technology affects individuals negatively. Moreover, it has been found that attention deficit and hyperactivity levels are high in those individuals who do not do sport regularly.
\end{abstract}

Keywords: sport, university student, hyperactivity, attention

\section{Introduction}

In our country as in world, hyperactivity and attention deficit in social life is important. Since periods of development of individuals show parallelism with school year, recently, ADHD has become important in education applications.

"Attention deficit hyperactivity disorder is a developmental disorder which makes trouble because of the features that inconvenience during maintaining and completing the tasks, activities in which hypermobility, rashness, impulsivity features are apparent" (Öktem, 2009). According to American psychiatric association diagnostic and statistical manual of mental disorders (2000), Attention deficit and hyperactivity disorder is identified as the most common childhood psychiatric disorder diagnosed among 3-7\% of children (cited by Ribeiro-Bicudo, 2016). Attention deficit and hyperactivity disorder is expressed as a frequently encountered problem. Although it is such a frequently encountered disorder, there is no certain information about its reasons (Öncü and Şenol, 2002). İt expressed as situation of hypermobility, restlessness, being energetic, being unable to concentrate on some areas for a long time (Abal, 2018).

According to Lewis and Miller (1990), If ADHD is identified with generally three titles, these are heredity, environmental factors, structural and functional differences in brain (cited by Doğan and Işıtan 2011). There are internal and external factors affecting attention. External stimulants are expressed as being acute and great, being contrast, that is, being opposed to the stimulants they are in, being movable, being repeated regularly, being unusual and new of the 
stimulant. And, internal stimulants are such factors as emotion, thought, needs, interests, wishes and expectations, things learnt before and characteristics (Barbaroğlu, 2011). ADHD is an important psychiatric disorder which shows high genetic transition in terms of its prevalence and effects on life quality. Despite its importance in terms of diagnosis and treatment, ADHD ethnology has not been enlightened very well, and the disorder is expressed as a complex problem occurring with effects of both genetic and environmental factors (Akgün et. al., 2011).

During normal life period of individuals, it is emphasised that early diagnosis and medication on ADHD is very important and development of strategies related to this field is also important (Biederman et. al., 2006). In this study, the purpose is to determine whether hyperactivity and attention deficit levels of adult individuals who do sport and do not sport differ according to some variances or not. It is thought that the study can be resource for studies to be conducted in this field and its results can guide families, teachers, psychologist, psychological counsellors, trainers, athletes and other fields related to the topic.

\section{Material and Method}

Carried out with scanning model, this study was applied to 353 students, who continue their education at Yuzuncu Yil University during 2017/2018 academic year, including 208 students who sport regularly and 145 students who do not sport. Reliability and validity of Turkish form of WHO's Adult Attention Deficit/Hyperactivity Disorder Self-Report Scale (ASRS-v1.1) was carried out by Dogan et. al. (2009). As statistical method, as well as descriptive statistics, Kruskal Wallis $\mathrm{H}$ test for multiple comparisons and Mann-Whitney $\mathrm{U}$ test for paired comparisons were used in the situations in which normality and homogeneity of variances were not provided. $\mathrm{p}<0.05$ was determined as significance level.

\section{Findings}

The main aim of this study is to determine hyperactivity and attention deficit level of adult individuals who do sport regularly and do not do sport.

Table 1. Evaluation of attention deficit levels in those who do sport and do not do sport (Mann-Whitney U)

\begin{tabular}{llllcc}
\hline Participants & $\mathbf{n}$ & Average of Rank & Total of Rank & u & p \\
\hline Those who do sport & 208 & 160.68 & 33421.50 & \multirow{2}{*}{11685.50} & $\mathbf{0 . 0 0}^{\text {*** }}$ \\
Those who do not do sport & 145 & 199.35 & 28706.50 & & \\
\hline
\end{tabular}

$\mathbf{p}<\overline{\mathbf{0 . 0 1}}$

When attention deficit levels in those who do sport and those who do not do sport are examined, significant difference has been detected in favor of those who do sport $(\mathrm{p}<0.01)$.

Table 2. Evaluation of hyperactivity levels in those who do sport and do not do sport (Mann-Whitney U)

\begin{tabular}{llllcc}
\hline Participants & n & Average of Rank & Total of Rank & u & p \\
\hline Those who do sport & 208 & 167.68 & 34878.00 & \multirow{2}{*}{13142.00} & $\mathbf{0 . 5 0}^{*}$ \\
Those who do not do sport & 145 & 189.24 & 27250.00 & & \\
\hline
\end{tabular}

$\mathbf{p}<\overline{\mathbf{0 . 0 5}}^{*}$

When hyperactivity levels in those who do sport and those who do not do sport are examined, significant difference has been found in favor of those who do sport $(\mathrm{p}<0.05)$.

Table 3. Evaluation of attention deficit according to siblings living at home (Mann-Whitney U)

\begin{tabular}{llcccc}
\hline Type of Family & $\mathbf{n}$ & Average of Rank & Total of Rank & u & p \\
\hline Extended Family & 249 & 187.91 & 46788.50 & 10232.50 & $\mathbf{0 . 0 2}^{*}$ \\
Elementary Family & 104 & 150.89 & 15692.50 & & \\
\hline
\end{tabular}

p $<0.05^{*}$

In evaluation of attention deficit according to siblings living at home significant difference has been found in favor of those number whose siblings living at home is low $(\mathrm{p}<0.05)$. 
Table 4. Evaluation of hyperactivity levels according to academic achievement (Kruskal Wallis $\mathrm{H}$ )

\begin{tabular}{lcccccc}
\hline Academic Achievement & $\mathbf{n}$ & Average of Rank & sd & $\mathbf{X}$ & $\mathbf{p}$ & Signicant Difference \\
\hline Low & 39 & 190.82 & & & & \\
Medium & 220 & 186.12 & 2 & 9.24 & $\mathbf{0 . 1 0 *}$ & $\begin{array}{c}\text { Between medium and } \\
\text { high academic level }\end{array}$ \\
High & 221 & 149.54 & & & &
\end{tabular}

p $<0.05^{*}$

In evaluation of hyperactivity levels according to academic achievement, significant difference has been found in favor of those whose academic achievements are high $(\mathrm{p}<0.05)$.

Table 5. Evaluation of attention deficit levels in those who do sport and do not do sport according to academic achievements (Kruskal Wallis $\mathrm{H}$ )

\begin{tabular}{lcccccc}
\hline Academic Achievement & $\mathbf{n}$ & Average of Rank & sd & $\overline{\mathbf{x}}$ & $\mathbf{p}$ & Signicant Difference \\
\hline Low & 39 & 172.00 & & & & Between medium and \\
Medium & 220 & 188.94 & 2 & 9.33 & $\mathbf{0 . 0 9}^{*}$ & high academic level \\
High & 221 & 150.72 & & & & \\
\hline
\end{tabular}

p $<0.05^{*}$

In evaluation of attention levels according to academic achievement, significant difference has been found in favor of those whose academic achievements are high $(\mathrm{p}<0.05)$.

Table 6. Evaluation of hyperactivity levels of participants according to housing status (Kruskal Wallis H)

\begin{tabular}{lcccccl}
\hline Place of Housing & $\mathbf{n}$ & Average of Rank & sd & $\mathbf{X}$ & $\mathbf{p}$ & \multicolumn{2}{c}{ Signicant Difference } \\
\hline Dormitory & 147 & 183.59 & & & & $\begin{array}{l}\text { Between those staying at } \\
\text { home and dormitory and those } \\
\text { staying at home with family }\end{array}$ \\
With Family & 102 & 153.20 & 2 & 8.16 & $\mathbf{0 . 1 7}^{*}$ &
\end{tabular}

$\mathbf{p}<\mathbf{0 . 0 5}$

In evaluation of hyperactivity levels of participants according to housing status, significant difference has been found in favor of those who stay at home $(\mathrm{p}<0.05)$.

Table 7. Evaluation of attention deficit of participants according to housing status (Kruskal Wallis $\mathrm{H}$ )

\begin{tabular}{lcccccc}
\hline Place of Housing & $\mathbf{n}$ & Average of Rank & sd & $\mathbf{X}$ & $\mathbf{P}$ & Signicant Difference \\
\hline Dormitory & 147 & 174.29 & & & & $\begin{array}{l}\text { Between those staying at dormitory } \\
\text { and with family and those staying at } \\
\text { home and with family }\end{array}$ \\
House & 102 & 156.50 & 2 & 9.98 & $\mathbf{0 . 0 7}$ \\
With Family & 104 & 200.93 & & & &
\end{tabular}

$\mathbf{p}<\mathbf{0 . 0 5}{ }^{*}$

In evaluation of attention deficit of participants according to housing status, significant difference has been found found in favor of those who stay at dormitory and with their family, and significant difference between those who stay at home and those who stay with their family has been detected in favor of those who stay at home $(\mathrm{p}<0.05)$.

\section{Discussion}

It is stated that symptoms of ADHD can be seen among university students frequently and can have negative effects on their academic achievements and psychological functionalities (Doğan et. al., 2008). Attention is important for processing of sport, working, education and mental functions as well as our many daily activities (Kumartaşli and Bastug, 2010).

Our study has been carried out with the purpose of evaluation of attention deficit and hyperactivity levels of individuals who do sport and do not do sport. In our study, a significant difference has been seen in favor of those doing sport when attention deficit levels of those doing sport and those who do not are examined $(p<0.01)$. That is, sport is considered to positively contribute to their attention control level and to exhibiting more positive behaviors against different variances that they face during their normal lives.

In Literature studies, it is stressed that students doing sport have higher attention control when compared to those who 
do not.(Öztürk et. al., 2016). It is pointed out that the attention control level of the children doing ski is better than those who do not dothe sport (Göktepe et. al., 2016). Also, the attention control level of the children (about 10-12 years) doing extreme sports has a higher rate when compared to the children who do not do these sport (Kartal et.al, 2016). When studies on physical activity are examined, it is stated that physical activity can be protective on ADHD and cure it (Hastürk and Şenışık, 2016), and that using regular physical activity as additional to stimulant medication will have positive effects on children with ADHD (Türksoylu et. al., 2017). It is also stated that even the short time exercises can contribute positive development to attention level of individuals (Çelik et. al., 2017). In another study, it is indicated that folklore exercise has positive effects on behaviors of children with ADHD (Topçu et. al., 2007). In the study of Tunç (2013), it is stated that exercises related to golf sport can lead to a significant difference on attention level of children. In the study of Adsiz (2010), it is pointed out that the sport which is done regularly and in accompany of a trainer contributes to attention development of 4-5 grade children positively. Akandere et. al (2010), point out that an 8 -week educational program positively affects the attention levels of students. Consequently, the conducted studies show parallelism with our study and support it.

In our study, when hyperactivity levels in those who do sport and those who do not do sport are examined, significant difference has been found in favor of those who do sport. $(\mathrm{p}<0.05)$. In accordance with these results, it is thought that sport contributes positively to hyperactivity levels, controlling themselves, behaving their behaviours and movements positively.

In literature studies, some skills of the individuals who have attention deficit together with hyperactivity spoil. It is stated that physical activity can be effective in reducing these problems and these kinds of studies need being conducted (Jiménez Palomar, 2013). Gómez (2017), state in his study that exercise and physical activity affect hyperactivity positively. In different studies, it is indicated that with medical treatment of children with attention deficit and hyperactivity, their doing racket sports contribute positively to the treatment (Pan C.Y et. al., 2016). Moreover, it is stated that sport training is effective and contribute positively in positively behaving of individuals with ADHD (O'Connor et. al., 2014).

Based on studies in literature, we can say that sport affects hyperactivity and attention deficit of individuals with ADHD positively and increases life quality. In our study, in evaluation of the results related to hyperactivity and attention levels according to academic achievement, a significant difference has been seen in favour of those whose academic achievements are high $(\mathrm{p}<0.05)$.

Yavuzer (2013), states that $90 \%$ of the children with ADHD are not productive enough at schools, and $90 \%$ of them are low successful, $20 \%$ of them have difficulty in reading, and $60 \%$ of them have serious difficulties in reading and writing, and $30 \%$ of them drop out.

It is stated that symptoms of ADHD can be seen among university students frequently and can have negative effects on their academic achievements and psychological functionalities (Doğan et. al., 2008).

That is, some skills of individuals with attention deficit as well as hyperactivity spoil. Deterioration of these skills affects academic achievements negatively. If individual does sport or exercise in his/her normal life, accordingly, it is thought that in his/her hyperactivity level there will be a fall and in his/her attention level there will be an increase. In this context, academic achievement of the individual will increase. The result of the study we carried out confirms this.

In a study, it is stated that physical training programs affects academic achievements and behaviours of children with ADHD positively (Abreu and Twuemulilatyi. 2017). With a similar result, Hillman et. al. say that moderate aerobic exercises can improve cognitive control of attention in adolescents, and moreover, can be a factor that supports academic achievement (Hillman et. al., 2009).

In our study, in evaluation of attention deficit according to the number of siblings living at home, a significant difference has been found in favour of those whose number of siblings living at home is low ( $<<0.05)$. It has been concluded that being crowded of the individuals living at the same home affects hyperactivity and attention levels of these individuals negatively, but when the number is low, hyperactivity and attention levels are affected positively.

In a study, it is stated that there is a positive significant difference between the number of siblings and attention control levels in those children doing ski sport (Göktepe et.al., 2016).

In another result of our study, in evaluation of hyperactivity and attention deficit levels of participants according to housing status, a significant difference has been detected in favor of those staying at home $(\mathrm{p}<0.05)$. Individual interacts with others in social networks at his/her school, in his/her family and in his/her environment as a necessity of life. In this interaction, he/she may face a lot of problems in many fields. These problems may affect some behaviors and emotions of the individual negatively. In this context, it is thought that individual should be selective about where he/she houses, that is, staying at a calm home rather than a crowded place affects his/her emotions and behaviours more 
positively. In our study, a significant difference has not been seen according to participants' gender, the high-school, educational level of father and mother ( $p>0.05)$.

In the studies that Atlı et. al. (2016), Kumartaş and Baştuğ (2010), Aydın (2017) conducted, a significant difference according to gender variance has not been seen.

As a result, it has been indicated that sport affects hyperactivity and attention deficit level positively. As a consequence of this positive effect, it is thought that sport contribute positive contributions to being high of individual's academic achievement and maintaining his/her life at peace with society. The studies conducted in this field show that sport activities may contribute positive contributions when used in educational programs in which individuals with ADHD take place. Development of programs by specialists about sport and attention topic is needed.

\section{References}

Abal1, O. (2018). Hyperactivity and lack of attention. Adeda Publishing.

Abreu, B. P., \& Twuemulilatyi, H. M. (2017). Physical Education treatment tothe students suffering from shortage of attention and hyperactivity in primary schools Podium, 12(1), 31-41.

Adsız, E. (2010). Elementary school age in children's attention to the development effect of sports. İzmir, Ege University, Health Sciences Institute, Physical education and Sport Department, Masters Degree.

Akandere, M., Bastug, G., Asan, R., \& Bastug, K. (2010). The effect of educational game over attention in children. Ovidius University Annals. Series Physical Education and Sport/Science, Movement and Health. 10(2), 325-330.

Akgün, G. M., Tufan, E., Yurteri, N., \& Erdoğan, A. (2011). Genetic Basis of Attention Deficit Hyperactivity Disorder. Current Approaches in Psychiatry, 3(1).

Atli, M., Yaşar, G., \& Özkan, Z. (2016). A Study on The Relationship Between Attention Deficit Hyperactivity Disorder and The Academic Success and Some Parameters of The Students of enrolled to the Physical Education and Sports Department. Yüzüncü Yil University Journal of Education Faculty, 13(1), 315-329.

Aydın, S. (2017). 12-18 Investigating of reaction seed and attention level at students who do exercise and who don't in the range of 12-18. Van YYÜ Institute of Educational Sciences. Physical Education and Sport Department: Masters Degree

Barbaroğlu, A. (2011). Child Psychology and Mental Health, Vize Publishing, Ankara.

Biederman, J., Monuteaux, M. C., Mick, E., Spencer, T., Wilens, T. E., Silva, J. M., Snyder L. E. \& Faraone, S. V. (2006). Young adult outcome of attention deficit hyperactivity disorder: a controlled 10-year follow-up study. Psychological medicine, 36(2), 167-179. https://doi.org/10.1017/S0033291705006410

Çelik, İ., Beyleroğlu, M., \& Hazar, M. (2017). An Investigation Of The Effect Of 4 Week Exercise Program On The Attentıon In The Trainıng Order On University Students. Electronic Turkish Studies, 12(25).

Doğan, Ö., \& Işıtan, S. (2011). Children who have attention deficit hyperactivity disorder and their education. N. Baykoç-Dönmez (Ed.), Children with Special Needs and Special Education (s.271-286), Eğiten Kitap. Ankara.

Doğan, S., Öncü, B., Varol Saraçoğlu, G., \& Küçükgöncü, S. (2008). Prevalence of ADHD Symptoms in University Students and Developmental, Academic and Psychological Factors Related to Symptom Level. Psychiatry in Turkiye, 10, 109-115.

Doğan, S., Öncü, B., Varol Saraçoğlu, G., \& Küçükgöncü, S. (2009). Validity and reliability of the Turkish version of the Adult ADHD Self-Report Scale (ASRS-v1.1). Anatolian Journal of Psychiatry, 10, 77-87.).

Göktepe, M., Akalın, T. C., \& Göktepe, M. M. (2016). An Analysis of Attention Levels of Children Involved in the Sport of Skiing.International Journal of Science Culture and Sport, 4(Special Issue 3), $722-731$. https://doi.org/10.14486/IntJSCS620

Gómez, A. G. (2017). GHA eta kirola; Hyperactivity and sport pain, Europe: Publicaciones Didácticas, 2017.

Hastürk, M. O., \& Şenışık, S. Ç. (2016). The Relationship Between Physical Activity and Mental Development in Children; Physical Activity in Attention Deficit -Hyperactivity Disorder and Disruptive Behavior Disorders. Turkiye Klinikleri Journal Of Sports Medicine-Special Topics, 2(2), 27-31.

Hillman, C. H., Pontifex, M. B., Raine, L. B., Castelli, D. M., Hall, E. E., \& Kramer, A. F. (2009). The effect of acute treadmill walking on cognitive control and academic achievement in preadolescent children. Neuroscience, 159(3), 1044-1054. https://doi.org/10.1016/j.neuroscience.2009.01.057

Jiménez, P. P. M. (2013). Evaluation of a sports program in modifying the symptoms of hyperactivity, inattention and 
impulsiveness applied to children with Attention Deficit Disorder. NURE Investigation, 10(67).

Kartal, R., Dereceli, Ç., \& Kartal, A. (2016). The Analysis of the Attention Levels of 10-12 Aged Children Playing Fencing. Sportif Bakis: Journal of Sports and Educational Sciences, 3(2), 82-88.

Kumartaşl1, M., \& Baştuğ, G. (2010). Examination of Attention Levels of Athletes Who Do Taekwondo, Karate and Muaythai. Ovidius University Annals, Series Physical Education and Sport. Science Movement and Health, 2, 521-524.

O’Connor, B. C., Fabiano, G. A., Waschbusch, D. A., Belin, P. J., Gnagy, E. M., Pelham, W. E., \& Roemmich, J. N. (2014). Effects of a summer treatment program on functional sports outcomes in young children with ADHD. Journal of abnormal child psychology, 42(6), 1005-1017. https://doi.org/10.1007/s10802-013-9830-0

Öktem, F. (2009). Attention deficit and hyperactivity disorder. (Ed.), Akçamete. Special Education for Special Education. Kök yayıncılık, Ankara.

Öncü, B., \& Şenol, S. (2002). The Etiology of Attention Defict Hyperactivity Disorder: An Integrative Approach. J. Clin. Psy., 5(2), 111-119.

Ozturk, M. E., Bayraktar, G., Öztürk, D., \& Tozoğlu, E. (2016). A Research on Attention Control Levels of the Students at Vocational School of Health Services in terms of Sports and Different Variables. International Journal of Science Culture and Sport (IntJSCS), 4(1), 76-83.

Pan, C. Y., Chu, C. H., Tsai, C. L., Lo, S. Y., Cheng, Y. W., \& Liu, Y. J. (2016). A racket-sport intervention improves behavioral and cognitive performance in children with attention-deficit/hyperactivity disorder. Research in developmental disabilities, 57, 1-10. https://doi.org/10.1016/j.ridd.2016.06.009

Ribeiro-Bicudo, L. A. (2016). Genetics Findings in Attention Deficit Hyperactivity Disorder. A Handbook of Attention Deficit Hyperactivity Disorder (ADHD) in the Interdisciplinary Perspective. Bentham Science Publishers Ltd. https://doi.org/10.2174/9781681081519116010005

Topçu, B., Yıldız, S., \& Bilgen, Z. T. (2007). The Effect of Folklore Exercise Program in Children Diagnosed with Attention Deficit/ Hyperactivity disorder (ADHD). Journal of General Medicine, 17(2), 89-93.

Tunç, A. (2013). The analysis of the attention levels of children playing golf. Masters Degree, Selçuk UniversityHealth Sciences Institute.

Türksoylu, A., Öztürk, Y., Ergün, M., \& Türksoylu, M. (2017). Investigation of the Effect of Regular Physical Activity on Children with Attention Deficit and Hyperactivity Disorder. Turkish Journal of Sports Medicine. 52, 5-5.

Yavuzer, H. (2013). School-Age Childhood with Models of Education and Development. (16. Volume). Remzi Bookstore. İstanbul.

\section{Copyrights}

Copyright for this article is retained by the author(s), with first publication rights granted to the journal.

This is an open-access article distributed under the terms and conditions of the Creative Commons Attribution license which permits unrestricted use, distribution, and reproduction in any medium, provided the original work is properly cited. 